\title{
Delay-Dependent Working Memory Impairment in Young-Adult and Aged 5-HT1BKO Mice as Assessed in a Radial-Arm Water Maze
}

\author{
Mathieu Wolff, ${ }^{1}$ Narimane Benhassine, ${ }^{1}$ Pierre Costet, ${ }^{2}$ René Hen, ${ }^{3}$ Louis Segu, ${ }^{1}$ \\ and Marie-Christine Buhot ${ }^{1,4}$ \\ ${ }^{1}$ Centre National de la Recherche Scientifique-UMR 5106, Laboratoire de Neurosciences Cognitives, Université de Bordeaux 1 , \\ 33405 Talence cedex, France; ${ }^{2}$ Laboratoire de Transgénèse, Université de Bordeaux 2, 33076 Bordeaux cedex, France; ${ }^{3}$ Center \\ for Neurobiology \& Behavior, Columbia University, New York, New York 10032, USA
}

\begin{abstract}
Serotonin (5-HT) plays a modulatory role in mnemonic functions, especially by interacting with the cholinergic system. The 5-HTIB receptor is a key target of this interaction. The 5-HTIB receptor knockout mice were found previously to exhibit a facilitation in hippocampal-dependent spatial reference memory learning. In the present study, we submitted mice to a delayed spatial working memory task, allowing the introduction of various delays between an exposure trial and a test trial. The 5-HT1BKO and wild-type mice learned the task in a radial-arm water maze (returning to the most recent presented arm containing the escape platform), and exhibited a high level of performance at delays of 0 and $5 \mathrm{~min}$. However, at the delay of $60 \mathrm{~min}$, only 5-HTIBKO mice exhibited an impairment. At a delay of $90 \mathrm{~min}$, all mice were impaired. Treatment by scopolamine $(0.8 \mathrm{mg} / \mathrm{kg})$ induced the same pattern of performance in wild type as did the mutation for short (5 min, no impairment) and long (60 min, impairment) delays. The 22-month-old wild-type and knockout mice exhibited an impairment at short delays (5 and $15 \mathrm{~min}$ ). The effect of the mutation affected both young-adult and aged mice at delays of 15, 30, and 60 min. Neurobiological data show that stimulation of the 5-HTIB receptor inhibits the release of acetylcholine in the hippocampus, but stimulates this in the frontal cortex. This dual function might, at least in part, explain the opposite effect of the mutation on reference memory (facilitation) and delay-dependent working memory (impairment). These results support the idea that cholinergic-serotonergic interactions play an important role in memory processes.
\end{abstract}

\begin{abstract}
Memory capabilities that depend on the functional integrity of the hippocampus appear to be particularly vulnerable to the aging process (Barnes and McNaughton 1985; Foster 1999). Much less information is available concerning age-related frontal cortical dysfunctions. Behavioral models of working memory in rodents, like the classical radial maze or alternation tasks, are not preferentially sensitive to frontal cortical dysfunction, as a nonnegligible part of the performance is under the control of the hippocampus (Shen et al 1996; Johnson et al. 2002). There exists ample data to indicate that the hippocampal formation plays a critical functional role in delayed-matching or nonmatching-toplace (DMP, DNMP, respectively; e.g., in humans: Eichenbaum et al. 1994; Kesner and Hopkins 2001; in rodents: Eichenbaum et al. 1994; Steele and Morris 1999; Clark et al. 2001). Another brain structure that appears as a good candidate to control working memory by use of extended retention intervals is the medial prefrontal cortex (MPFC). In rodents, this structure has often been described as playing a role in some aspects of working memory (for review, see Granon and Poucet 2000), such as maintaining information across delays or manipulating such information to select a response. Ragozzino et al. (1998) have recently proposed that the rat PFC is specialized in this function, with the prelimbic-infralimbic (PL-IL) area being involved more specifically in allocentric spatial working memory. The PL should not be crucial to maintaining specific information over delays, but
\end{abstract}

\section{${ }^{4}$ Corresponding author.}

E-MAIL buhot@neurocog.u-bordeaux.fr; FAX (33) $\mathbf{5 4 0 0 0 8 7 4 3 .}$ Article and publication are at http://www.learnmem.org/cgi/doi/10.1101/ Im.60103. should contribute more precisely to planning prospective search behavior in spatial tasks (Seamans et al. 1995). However, recent findings suggest that the rat PL-IL is involved in delay-dependent performance in nonspatial tasks (Delatour and Gisquet-Verrier 1999), whereas it may not be implicated in spatial working memory performance as tested using the classical version of the radial-arm maze (Delatour and Gisquet-Verrier 1996).

The role of serotonin (5-hydroxytryptamine, 5-HT) in the modulation of learning and memory has been the subject of numerous investigations, demonstrating in particular that this function is mediated via an active interaction of 5-HT with the cholinergic system (Cassel and Jeltsch 1995; Steckler and Sahgal 1995; Ruotsalainen et al. 1998; Buhot et al. 2000; Lehmann et al. 2000, 2002; Buhot et al. 2003b). The 5-HT1B receptor is a key target involved in this interaction (Buhot et al. 1995; Cassel et al. 1995; Buhot 1997). Stimulation of 5-HT1B receptors located on hippocampal terminals of septal cholinergic neurons decreases the release of ACh, thus reducing the efficacy of the septo-hippocampal pathway (Cassel et al. 1995). In contrast, stimulation of 5-HT1B receptors in the frontal cortex increases ACh release in this region, probably by acting on GABAergic interneurons (Consolo et al. 1996). Microdialysis studies in rats suggest that the concentration of acetylcholine (ACh) increases in the prefrontal cortex during the performance of delayed working memory task, whereas it increases preferentially in the hippocampus when the subject is performing a reference memory task (Hironaka et al. 2001).

In memory models involving a predominant recruitment of the hippocampus (spatial reference memory), we have observed that intrahippocampal administration of a specific 5-HT1B ago- 
nist impairs performance of rats in a radial maze (Buhot et al. 1995), whereas 5-HT1BKO mice, in particular aged knockout mice, exhibit learning facilitation in the Morris water maze (Malleret et al. 1999; Buhot et al. 2003a; Wolff et al. 2003).

The aim of the present study was to evaluate whether the genetic deletion of the 5-HT1B receptor would change the performance of mice in a delayed spatial working memory task. Our first aim was to generate a working memory paradigm involving temporal interference (delays) between an exposure trial and a retention trial, using a radial-arm water maze. The second objective was to evaluate the performances of young-adult 5-HT1BKO mice in this task, especially after the introduction of various delays, our hypothesis being that knockout mice would display impairment when the task requires the retention of information over long delays. The third aim of the study was to test the effect of scopolamine, a muscarinic cholinergic antagonist. The last experiment was conducted to evaluate whether this task was aging dependent, and to what extent this age effect could interact with the mutation.

\section{RESULTS}

\section{Experiment 1}

\section{Working Memory Training}

Between days 1 and 22, both wild-type and knockout mice increased TA/V over days (Fig. 1A). ANOVA revealed significant effects of day $[\mathrm{F}(21,420)=17.16 ; \quad P<0.0001]$, genotype $[\mathrm{F}(1,20)=5.37 ; P=0.03]$, but a nonsignificant effect of the inter- action genotype $\mathrm{x}$ day. Mice of both genotypes learned the task in a similar manner, but knockout mice exhibited a slight facilitation. Similar to TA/V, the number of incomplete visits (IV) increased equally progressively with the advance of training [day effect, $\mathrm{F}(21,420)=9.00 ; P<0.0001]$, but no significant genotype effect was observed.

\section{Delay Effects}

The global analysis revealed an overall significant effect of delay $[\mathrm{F}(4,80)=10.40 ; P<0.0001]$, but nonsignificant effects of the genotype or the interaction genotype $\mathrm{x}$ delay $[\mathrm{F}<1]$ (Fig. 1B).

\section{0-, 1-, and 5-Min Delays}

Mice of both genotypes performed the task equally well whatever the delay, reaching an asymptotic level of performance above chance level (all $P$ s $<0.01$ ). Thus, short RIs do not affect the performance of mice, whatever their genotype.

\section{0-Min Delay}

For this long delay, the performance of knockout mice dropped to chance level $(P=0.36)$, whereas wild-type mice continued to exhibit above chance level performance $(P=0.0002)$. ANOVA revealed a significant effect of the genotype $[\mathrm{F}(1,20)=14.09$; $P=0.0013]$.

\section{0-Min Delay}

The performance of mice of both genotypes decreased in the same manner and fell to chance level (both Ps >0.35). At this

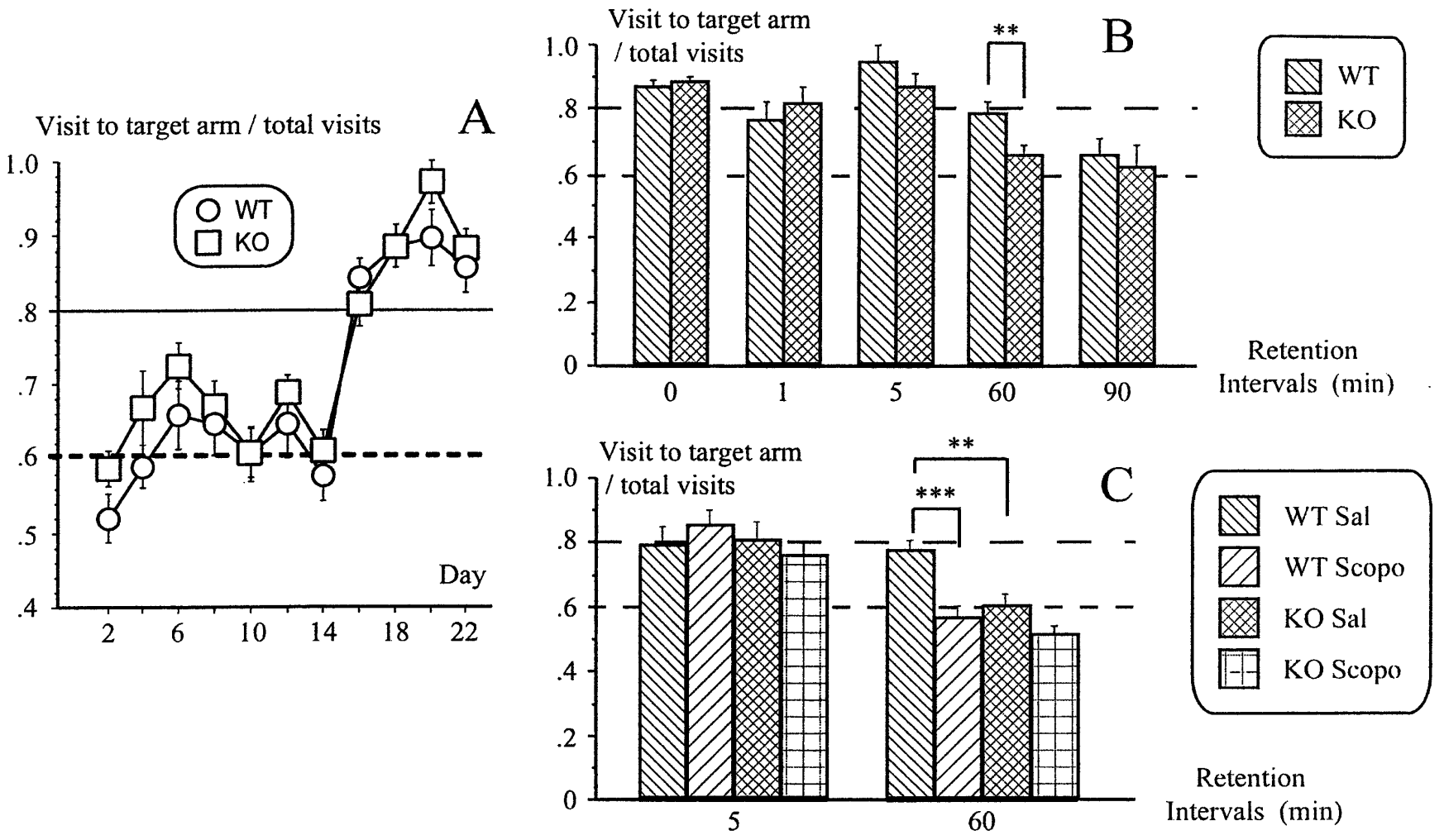

Figure 1 (A) Performance on test trials in basic learning (without delay, i.e., delay 0 min) of wild-type and 5-HT1BKO (KO) mice across days (day: average measure on two successive days; i.e., 6 -trial blocks). The performance is evaluated by the mean ( \pm SEM) value of the ratio, visit to target arm/total number of visits. (B) Performance of wild-type and 5-HT1BKO mice on test trials depending on the duration of the retention interval. Retention intervals were $0,1,5,60$, and $90 \mathrm{~min}$. (C) Effects of scopolamine (Scopo) administration ( $0.8 \mathrm{mg} / \mathrm{kg}$, i.p.) as compared with saline (Sal) on performance of wild-type and 5-HT1BKO mice on delayed retention intervals. Retention intervals were 5 and 60 min. The long-dashed horizontal lines represent the threshold level of performance above chance level; the short-dashed horizontal lines represent performance at chance level. $\left({ }^{\star \star *}\right) P<0.0005$; $\left({ }^{\star *}\right)$ $P=0.001$.

\section{Learning \& Memory}

www.learnmem.org 
delay, therefore, mice had completely forgotten the platform location.

\section{Effect of Scopolamine}

\section{Injection Effect}

The analysis did not reveal any difference in performance between non-injected and Sal-injected conditions at delays 5 and 60 min (for both modalities of injection time, i.e., before ET or before TT), suggesting that the injection per se did not disturb the performance.

\section{Injection Timing}

The comparison between injections before ET and before TT at delay $60 \mathrm{~min}$ did not yield significant statistical differences, whether Sal or Scopo was injected, suggesting that the time of injection per se did not change the level of performance. We thus pooled both modalities for further analyses.

\section{Effect of Scopolamine Treatment}

Performance decreased over delays 5-60 min [delay effect, $\mathrm{F}(1,20)=43.57 ; P<0.0001]$ (Fig. 1C). ANOVA revealed significant effects of the genotype $[\mathrm{F}(1,20)=5.97 ; P=0.02]$, treatment $[\mathrm{F}(1,20)=8.05 ; P=0.01]$, and of the interaction treatment $\mathrm{x}$ delay $[\mathrm{F}(1,20)=5.58 ; P=0.03]$. A significant effect of the genotype was observed at delay $60 \mathrm{~min}$ after Sal injection $[\mathrm{F}(1,20)=14.59$; $P=0.001]$, confirming the selective impairment of knockout mice at this delay $(P=0.95)$. At this long delay, the effect of scopolamine completely abolished the genotype effect $[\mathrm{F}(1,20)=1.50 ; P=0.24]$, attesting that the treatment had affected the performance of wild-type mice, which dropped from a significant high level of performance $(P=0.0002)$ to chance level $(P=0.40)$ of performance, similar to that of knockout mice.

\section{Experiment 2}

\section{Working Memory Training}

Between days 1 and 22, both wild-type and knockout mice, either young adult or aged, increased their performance (TA/V) over days. ANOVA revealed a significant effect of day $[\mathrm{F}(21,714)=13.94$; $P<0.0001]$, but no significant effects of genotype, age, or of the interaction genotype $\mathrm{x}$ age. Similar to Experiment 1 , the number of incomplete visits (IV) increased progressively with the progression of training [day effect, $\mathrm{F}(21,777)=11.63 ; P<0.0001$ ], and was associated with nonsignificant genotype or age effects, but a significant genotype $\mathrm{x}$ age interaction $[\mathrm{F}(1,37)=6.62 ; P=0.01]$, an effect due to 3 -month-old mice $[\mathrm{F}(1,22)=11.05 ; P=0.003]$, not 22-month-old mice. The 3-month-old knockout mice exhibited incomplete visits less frequently than 3-month-old wild type. The age effect was observed in wild-type mice $[\mathrm{F}(1,18)=7.57$; $P=0.01]$ only (Fig. 2). This measure of behavior indicated that 3-month-old knockout mice developed a strategy of research similar to that exhibited by 22-month-old (wild-type and knockout) mice, that is, an impairment in a self-correcting strategy ability.

\section{Delay Effect}

A global analysis revealed significant effects of delay $[\mathrm{F}(5,170)=17.86 ; \quad P<0.0001], \quad$ genotype $[\mathrm{F}(1,34)=50.15$; $P<0.0001]$ and age $[\mathrm{F}(1,34)=24.39 ; P<0.0001]$. In addition, the significant effects of the interactions genotype $\mathrm{x}$ delay $[\mathrm{F}(5,170)=6.04 ; P<0.0001]$, age $\mathrm{x}$ delay $[\mathrm{F}(5,170)=10.35$; $P<0.0001]$ and genotype $\mathrm{x}$ age $\mathrm{x}$ delay $[\mathrm{F}(5,170)=3.80$; $P=0.003$ ] allowed us to examine separately the pattern of results at each of the delays (Fig. 3).

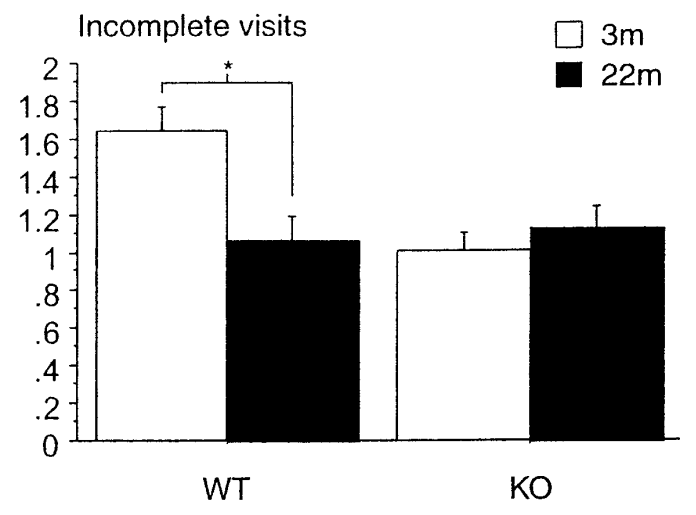

Figure 2 Incomplete visits during training (Experiment 2, stage 1). The values are expressed in terms of mean ( \pm SEM) number of incomplete visits per day (sum of the three daily trials). (3m) 3-months old; (22m) 22-months old; $\left({ }^{*}\right) P=0.01$.

\section{0-Min Delay}

No significant effects of genotype or age were observed when no delay was introduced between EE and ET. Furthermore, the performance of all groups of mice was significantly superior to chance level, as revealed by Student's t tests (all $P s<0.001$ ). Thus, as for training, all groups of mice mastered the basic task, whatever their genotype or age.

\section{5-Min Delay}

The 22-month-old mice exhibited a large decrease of performance in both genotypes, as revealed by the significant effect of age $[\mathrm{F}(1,34)=61.25 ; P<0.0001]$. In fact, the performance of 22month-old wild-type and knockout mice fell to chance level (both Ps > 0.34). By comparison, young mice of both genotypes continued to perform the task above chance level (both Ps $<0.0001)$.

\section{5-Min Delay}

ANOVA revealed significant effects of genotype $[\mathrm{F}(1,34)=45.20$; $P<0.0001]$, age $[\mathrm{F}(1,34)=59.96 ; P<0.0001]$ and age $\mathrm{x}$ genotype interaction $[\mathrm{F}(1,34)=22.90 ; P<0.0001]$. The 22-month-old mice were still impaired, but a significant effect of genotype in 3 -month-old mice $[\mathrm{F}(1,17)=92.96 ; P<0.0001]$ revealed that 3 -month-old knockout mice were also impaired $(P=0.32)$. Only 3 -month-old wild-type mice continued to perform the task above chance level $(P<0.0001)$.

\section{0-Min Delay}

In contrast to the two former delays ( 5 and $15 \mathrm{~min}$ ), no significant effect of age $(\mathrm{F}<1)$ was revealed by the global analysis of performance at this delay. However, ANOVA revealed significant effects of genotype $[\mathrm{F}(1,34)=23.98 ; P<0.0001]$ and age $\mathrm{x}$ genotype interaction $[\mathrm{F}(1,34)=7.43 ; P=0.01]$. A significant effect of age was observed in knockout mice only $[\mathrm{F}(1,17)=5.62$; $P=0.03]$, which was due to a slightly higher performance of 22month-old knockout mice as compared with 3-month-old knockout mice. Nevertheless, both groups of knockout mice performed at chance level at this delay (both $P \mathrm{~s}>0.10$ ). By comparison, no significant effect of age in wild-type mice $[\mathrm{F}(1,17)=2.67$; $P=0.12]$ showed that 22-month-old wild-type mice performed the task above chance level $(P=0.02)$, as also did the 3 -monthold wild-type mice $(P<0.0001)$, showing that they still performed the task well at this long delay. Taken together, the data showed a main genotype effect for this delay, without any consistent age effect. 


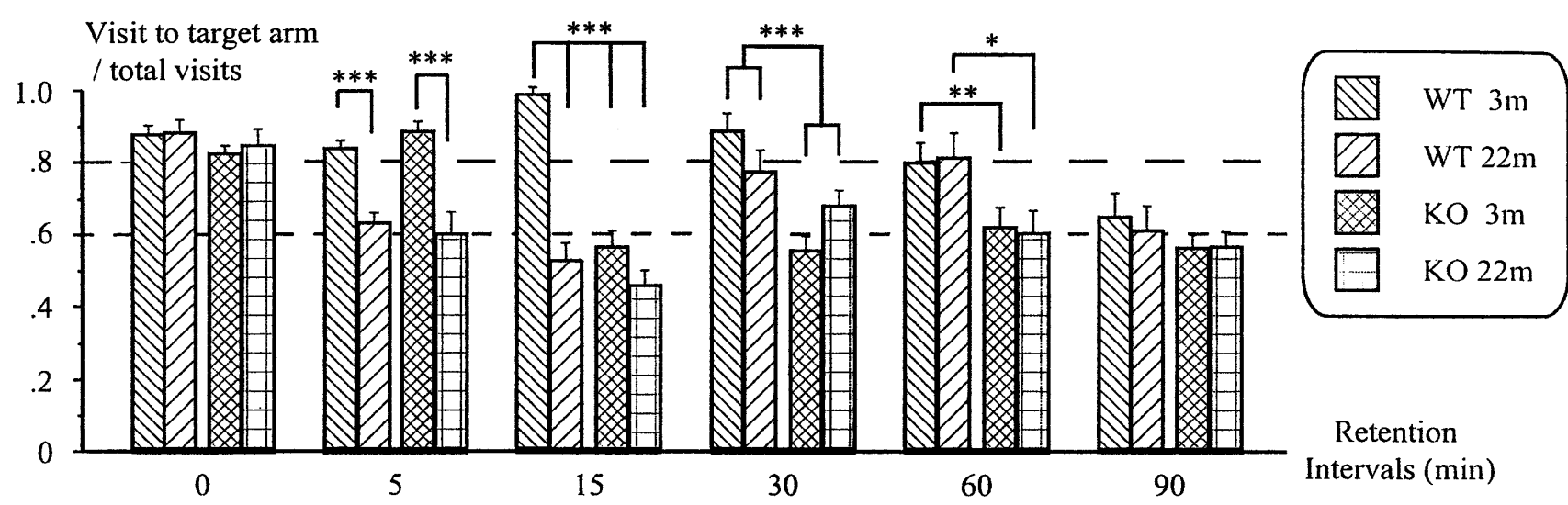

Figure 3 Effects of aging on performance of wild-type and 5-HT1BKO mice on delayed retention intervals. Retention intervals were $0,5,15,30,60$, and 90 min. (3m) 3-months old; (22m) 22-months old. $\left({ }^{* * *}\right) P<0.0001 ;\left(^{* *}\right) P=0.01 ;\left({ }^{*}\right) P<0.05$.

\section{0-Min Delay}

Knockout mice were impaired whatever their age, their performance dropping to chance level (both $P$ s $>0.80$ ). In contrast, wild-type mice continued to perform the task above chance level, whatever their age (3-month-old, $P=0.003$; 22-month-old, $P=0.015)$. ANOVA revealed a significant genotype effect $[\mathrm{F}(1,34)=11.09 ; P=0.0015]$.

\section{0-Min Delay}

No between-group differences were found for this delay, because the performance of all mice fell to chance level (3-month-old wild type, $P=0.50$; 22-month-old wild type, $P=0.94$; 3-monthold knockout, $P=0.20 ; 22$-month-old knockout, $P=0.31$ ). For this delay, all mice had completely forgotten the location of the platform.

\section{DISCUSSION}

The main results of the present study showed that both wild-type and knockout mice, independent of their age, were found to be able to learn the task (without delay), as they all reached an asymptotic level of performance at around $20 \mathrm{~d}$ of training. Young-adult and mature 5-HT1BKO and wild-type mice exhibited a high level of performance at short ( 1 and 5 min) delays. However, at a delay of $60 \mathrm{~min}$, only knockout mice exhibited an impairment. At a delay of 90 min, mice of both genotypes were impaired. Treatment by scopolamine $(0.8 \mathrm{mg} / \mathrm{kg})$ induced the same pattern of performance in wild type as did the mutation for short (5 min, no impairment) and long (60 min, impairment) delays. Aged knockout and wild-type mice exhibited an impairment at short delays (5 and $15 \mathrm{~min}$ ). The effect of the mutation affected both young-adult and aged mice at the delays of 15,30 , and $60 \mathrm{~min}$.

\section{Relevance of the Working Memory Paradigm}

This paradigm allowed us to demonstrate in particular that the deletion of the gene coding for the 5-HT1B receptor and aging are not critical to acquire the basic task, that is, to complete the different aspects of the task that are not directly linked to the presence of temporal interference. The nature of the information to be encoded being spatial, it is likely that the hippocampal formation was the main structure controlling this basic working memory learning, as has been reported repeatedly (e.g., Olton et al. 1979; Poucet and Buhot 1994; Xavier et al. 1999).

At the time the mice were submitted to delay tests, they were overtrained, and 0-min delay sessions were used as controls to assess delay effects. Young-adult and mature wild-type mice exhibited successful performance for all delays inferior to $90 \mathrm{~min}$.
These data suggest that the present experimental protocol is able to evaluate delay-dependent performance in working memory. Numerous studies indicate that working memory is evaluated efficiently in cases when the retention interval between the exposure and the test trial is increased (Floresco et al. 1997). In the task that we adapted for the mouse, performance at increasing delays will depend on a set of distinct cognitive abilities, such as attentional capacities, behavioral flexibility, and response selection within a familiar spatial context. These cognitive operations probably respond to some attributes of the hippocampus and some others of the PFC. PFC lesion in rats induces working memory deficits as a result of poor temporal encoding and increased susceptibility to interference (Granon et al. 1994). Converging data suggest that delay-related firing of prefrontal cortical neurons, which display sustained discharge during the entire length of the delay, except in the absence of mnemonic load, is an essential mechanism for holding information on line for the time necessary to adapt a response (for reviews, see Goldman-Rakic 1990; Laroche et al. 2000; Fuster 2001). In primates and humans, the PFC seems to be critically involved in working memory when long retention intervals are used (Milner et al. 1985). In contrast, delay-independent impairment in working memory seems more frequently linked to a dysfunction of the septo-hippocampal system (Shen et al 1996; Johnson et al. 2002). Nevertheless, both structures are necessary to solve the working memory task, and there is no doubt that hippocampal-prefrontal cortex connection is involved in a process through which recently acquired spatial information is used to organize integrated response strategies in a prospective manner (Floresco et al. 1997; Laroche et al. 2000).

In summary, our experimental situation, which is adapted for mice, allows us to evaluate delay-dependent deficits in a time window involving a range of short-to-long delays, the longest (90 min) corresponding to the memory load limit of the normal young-adult mouse's performance.

\section{Effect of Aging}

A deleterious effect of age on performance was observed at 5- and 15-min delays only. For longer delays (30 and $60 \mathrm{~min}$ ), 22month-old wild-type mice exhibited the same resistance to temporal interference as younger mice (3-month-old from Experiment 2, and 10-month-old mice from Experiment 1). Thus, our results revealed a dissociation between short $(<30 \mathrm{~min})$ and long (>30 min) delays, with aging having a deleterious effect only for the former. Such a paradoxical effect of aging has already been reported by Zyzak et al. (1995) with aged rats performing as well as young rats only when the memory delay was extended and 
interference was elevated. However, other studies reported that aged rats, in contrast to younger (3 or 12 months old) rats, are impaired for all delays extending from 5 to 120 min (Frick et al. 1995). Moreover, aged rats make disproportionately more errors than young rats when the working memory load increases (Bimonte el al. 2003). Considering the fact that working memory processes may involve different cerebral circuits depending on the difficulty of the task and the length of the delay(s) in use, the effect of aging on working memory abilities might be highly dependent on the cognitive requirement of the task, and cannot be easily generalized (in particular in monkeys, for examples, see Bachevalier and Mishkin 1986; Rapp and Amaral 1989). In addition, Lee and Kesner (2003) demonstrated that a mnemonic time window is a critical factor in dissociating the function of the (rat) hippocampal system from that of the MPFC; both structures process short-term spatial memory in parallel, but the dorsal hippocampus becomes highlighted as the time window for memory shifts from short term $(10 \mathrm{sec})$ to intermediate term $(5 \mathrm{~min})$. When the task difficulty increases and requires prospective coding of a sequence of several spatial items during a long-term delay (30 min), the interactive communication between the hippocampus and mPFC might become intensified (Floresco et al. 1997). The fact that 22-month-old wild-type mice were impaired at short, but not longer delays, might be related to a possible temporal dissociation between hippocampal and PFC functions.

Several studies reported that multiple dysfunctions in the hippocampus are associated with aging, thus affecting various aspects of cognition (for a recent review, see Rosenzweig and Barnes 2003). Furthermore, aging is associated with severe defects in hippocampal synaptic plasticity (Foster 1999), especially during the late phase of long-term potentiation (Bach et al. 1999). The hippocampus is more critically regulated by calciumdependent pathways than the cortex, and becomes, as a possible result, more sensitive to the age-induced down-regulation of calcium (Hartmann et al. 1996; Blalock et al. 1999). The cholinergic septo-hippocampal pathway is specifically altered in aged rats, which are more sensitive to a cholinergic muscarinic blockade than young rats (Nilsson and Gage 1993). By comparison, basal forebrain cholinergic projections to the cortex are not robustly affected by aging (for review, see Sarter and Bruno 1998). Both cholinergic pathways are active within a 15-min delay, but only the Nucleus Basalis Magnocellularis (NBM)-cortical pathway remains active when the delay exceeds 15 min (Durkin 1992). Recent electrophysiological data have provided further knowledge about delay-dependent mechanisms underlying working memory. Burette et al. (2000) demonstrated that improvement in performance with a 30-min delay in a spatial trial unique DNMP task is correlated with synaptic depression during the delay and a long-lasting depression of synaptic efficacy in the hippocampoprefrontal cortex pathway of rats. Synaptic depression may represent an anticonsolidation signal in tasks that do not require permanent storage of new information (Laroche et al. 2000).

These findings bring some light to our results, showing a delay-dependent dissociation in the performance of aged wildtype mice. Thus, the fact that aged wild-type mice were impaired at short delays may be explained by the recruitment of an agesensitive septo-hippocampal pathway, whereas the fact that the same mice were not impaired at longer delays may be explained by a switch toward the main control by the NBM-cortical pathway, which might be less sensitive to the effect of aging. However, further direct evidence is needed to verify this hypothesis.

\section{Effect of Scopolamine Treatment}

The fact that scopolamine had the same detrimental effect when injected either before the exposure trial or before the test trial, suggests a role for active muscarinic cholinergic mechanisms on acquisition, as well as retrieval of spatial items. The encoding hypothesis is supported by both animal (Soffié et al. 1986) and human (Ghoneim and Mewaldt 1975, 1977; Hasselmo and Wyble 1997) studies showing that scopolamine produces deficits when injected before initial acquisition. However, some authors have also argued for a role of the cholinergic system in retrieval or in both acquisition and retrieval (Beatty and Bierley 1986). Our results support the combined hypothesis (see also Izquierdo 1989) with the same pattern of disturbance observed, whatever the time of injection.

Scopolamine is generally found to disrupt spatial learning, especially in working memory tasks using systemic (e.g., Beatty and Bierley 1986; Poucet and Buhot 1989) or intracerebral (intrahippocampal: Brito et al. 1983; Buhot et al. 1995; intra-PFC: Granon et al. 1995; intra-thalamic: Mitchell et al. 2002) administration. We demonstrated (Experiment 1) that scopolamine did not interfere with performance for a short ( $5 \mathrm{~min}$ ) delay, but did interfere for a long $(60 \mathrm{~min})$ delay in wild-type mice. Our results are in agreement with Buresova et al. (1986) findings showing that scopolamine has no effect in overtrained rats, even in a reference memory task, and that the deleterious effect of the drug on the working memory component of the task is proportional to the length of retention delays $(5,10,20,40 \mathrm{~min})$. It is possible that, at the time of delay testing, our mice were sufficiently overtrained to resist to the effect of scopolamine at short delays.

\section{Role of the 5-HTIB Receptor}

The deletion of the 5-HT1B was found to be associated with a specific deterioration of working memory performance as assessed by use of an RI equal or superior to $15 \mathrm{~min}$, without affecting general learning abilities. However, the fact that mature knockout mice presented a slight facilitation as compared with age-matched wild-type mice in Experiment 1, not in Experiment 2 , might be accounted for by the age of the subjects (10-monthold vs. 3-month-old, respectively). We observed previously that the genotype effect in a spatial learning task is stronger in quite mature adult mice (6-10-months-old) than in younger (6 wk to 3-months-old) knockout mice (M.C. Buhot, unpubl.). The analysis of incomplete visits highlighted the fact that young-adult knockout mice behaved like aged wild-type or knockout mice during the training period; they did not develop as did youngadult wild type, an efficient pattern of hesitation (self-correction). If this behavior was not associated with a deficit in the acquisition of the basic task, it may nevertheless have interfered with the ability to solve the task when it became effortful (long delays). This behavior might be predictable of weaker PFC-dependent working memory performance, as the PFC is also involved in decision making (for review, see Krawczyk 2002), moreover, in effort-based decision making (Granon et al. 1994; Walton et al. 2002).

The 5-HT1B receptor does not seem to be implicated in working memory involving short RIs, as no differences were observed between the performance of wild-type and knockout mice for delays 0,1 , and $5 \mathrm{~min}$. Only the delays 15,30 , and $60 \mathrm{~min}$ induced this genotype effect. Aged knockout mice were found impaired at all delays due to an age effect at short delays (5 and $15 \mathrm{~min}$ ) and to the deletion of the 5-HT1B receptor at longer delays (equal or superior to $15 \mathrm{~min}$ ). These results are in contrast to our former results showing that young-adult and aged 5-HT1BKO mice exhibited facilitation in the acquisition of a spatial reference memory task, but not for recall or in long term (8 and 30 d) retention (Malleret et al. 1999; Buhot et al. 2003a; Wolff et al. 2003). Moreover, the cognitive requirement of the spatial working memory task used in the present study is quite 
different from that of spatial reference memory. Schematically, the former task requires the selective retrieval of the trial-unique information and, as such, the memory demand is of the anticonsolidation type (Laroche et al. 2000). In contrast, the spatial reference memory task with repeated exposure to the same spatial information (fixed platform location) basically requires memory consolidation.

Treatment by scopolamine $(0.8 \mathrm{mg} / \mathrm{kg})$ induced the same pattern of performance in wild type as did the mutation for short (5 min, no impairment) and long (60 min, impairment) delays. This suggests the existence of a possible common underlying mechanism of action between cholinergic blockade and 5-HT1B gene-deletion. Microdialysis data indicate that the stimulation of 5-HT1B receptors located on GABAergic interneurons in the frontal cortex enhances $\mathrm{ACh}$ release in this region (Consolo et al. 1996), thus showing a contrasting function as compared with its facilitatory effect on ACh release in the hippocampus, due to the direct inhibitory influence on septal cholinergic afferences to the hippocampus (Cassel et al. 1995). In these conditions, the genetic inactivation of 5-HT1B receptors might have inhibitory influence on frontal cortical functions, as it was found to selectively improve hippocampal-dependent learning (Malleret et al. 1999; Buhot et al. 2003a; Wolff et al. 2003).

The effects observed in the present study might be explained by compensatory mechanisms due to the mutation. So far, there is no available data concerning plasticities in the cholinergic system of the 5-HT1BKO mouse. The only findings demonstrate that the basal as well as $\mathrm{K}+$-evoked 5 -HT release in the frontal cortex and ventral hippocampus do not differ between wild-type and knockout mice (Trillat et al. 1997).

The dual role played by the 5-HT1B receptor in the control of ACh release in the hippocampus versus prefrontal cortex might contribute to the differential temporal dynamics of cholinergic activation in the septo-hippocampal versus NBM-cortical pathways during a delayed spatial working memory task (Durkin 1992). The facilitatory effect of 5-HT1B receptors on the activity of the NBM-PFC cholinergic pathway, and the lack of this influence in 5-HT1BKO mice could account for their selective working memory deficits for long delays.

At least part of the present findings demonstrated a large consistency between neurobiological data, which show a dissociation for the role played by the 5-HT1B receptor in the release of acetylcholine in the hippocampus on one way, and in the frontal cortex on another way, and behavioral data that show the opposite effects of the 5-HT1B receptor gene deletion on longterm memory (facilitation) and working memory (impairment). These results support the idea that cholinergic-serotonergic interactions play an important role in memory systems and highlight the problem of the eventual existence of global memory enhancers, as a given drug (for example, a 5-HT1B antagonist) may have a positive effect on hippocampal-dependent functions, but also have a deleterious effect on prefrontal cortical-dependent functions. The next step of this approach will thus be to extend this study using a psychopharmacological strategy.

\section{MATERIALS AND METHODS}

\section{Animals}

The subjects were male $129 / \mathrm{Sv}$ wild-type and homozygous 5-HT1B knockout (5-HT1BKO, knockout) mice. On receipt from the breeding colony (Laboratoire de Transgénèse, Université de Bordeaux 2), mice were housed individually in standard transparent laboratory cages $(26 \times 12 \times 14 \mathrm{~cm})$ in a temperaturecontrolled $\left(22 \pm 1^{\circ} \mathrm{C}\right)$ colony room, adjacent to the experimental room. Mice had $\sim 1$ month to acclimatize to the new facility after transfer from the breeding colony before testing. They were maintained on a 12:12 light-dark artificial cycle (lights on at 6:00 h) and provided with food and water ad libitum. They were tested during the light phase between 10:00 and 17:00 h. One week before the beginning of the experiments, the mice were handled each day by the experimenter. The genotype of each mouse was controlled at the end of the experiments. All experimental procedures were conducted in accordance with the European Communities Council Directive of 24 November 1986 (86/ 609/EEC).

\section{Apparatus}

The water maze was a white circular swimming pool $(140 \mathrm{~cm}$ in diameter; sidewalls $40-\mathrm{cm}$ high), filled with water (30-cm depth) maintained at $20^{\circ} \mathrm{C}$, which was made opaque by the addition of a nontoxic white paint (Pebeo). It was located in a room providing various distal cues. Inside the pool was a removable floating eight radial-arm maze structure made of polystyrene. The arms $(60 \mathrm{~cm}$ long $\times 10 \mathrm{~cm}$ width), with 8 -cm height transparent sidewalls, extended from a central area $(20 \mathrm{~cm}$ in diameter). A removable platform $(7 \mathrm{~cm}$ long $\times 10 \mathrm{~cm}$ width) made of transparent Plexiglas, positioned such that its top surface was $0.5 \mathrm{~cm}$ below the surface of the water, served as the refuge from the water, and was located at the extremity of one arm. A video camera fixed to the ceiling of the room was connected to a video recorder and a computer (Videotrack) located in an adjacent room that received the individual home cages of mice currently tested. For the purpose of the present experiment, only three arms of the maze were used, the other arms being blocked by removable opaque Plexiglas doors.

\section{Behavioral Procedure}

\section{Prelearning in the Standard Morris Water Maze}

Mice were first submitted to the classical reference memory task with the hidden platform in the open water maze as described in Malleret et al. (1999) to ensure that they had acquired basic procedural components of the task as well as a correct representation of the environment. Furthermore, a visually guided orientation test with a conspicuous black cylinder placed on the top of the platform attested that all mice that later performed the working memory task exhibited normal visual and sensorimotor abilities and motivation (data not shown; see Malleret et al. 1999).

\section{Pretraining in the Radial-Arm Water Maze}

Prior to learning, each mouse received a pretraining session that consisted of placing the mouse on the platform, where it had to stay at least $15 \mathrm{sec}$, followed by a 40 -sec swimming period starting from the central area and ending when the mouse found the platform and stayed there for a subsequent 15-sec period. This procedure was repeated four times with the platform occupying different arms' extremities (except arms that were later used during learning proper). During this stage, the water maze was surrounded by white curtains, which avoided the use of visual extramaze cues by mice. The platform was visually salient by the presence of a conspicious black cylinder placed on its top.

\section{Basic Spatial Working Memory Training (Stage 1)}

A total of 24 hours later, the mice were submitted to proper training, with the curtains withdrawn. Each day, they were submitted to three sessions. The intersession interval was $2 \mathrm{~h}$, which minimalizes the risk of interference from one session to the next. Each session comprised an exposure trial (ET) and a test trial (TT) (Fig. 4A). During the ET, only one arm was available and contained the hidden platform (target arm, TA). Released from the central area, the mouse had to reach the platform, where it was allowed to remain for $15 \mathrm{sec}$. During training, the TT occurred immediately (delay $0 \mathrm{~min}$ ), the mouse was placed back in the central area and allowed to return to the platform, but at this stage, three arms were now available. The TT terminated when the mouse climbed onto the platform, where it was allowed to stay for $15 \mathrm{sec}$ before it was returned to its home cage, located beneath a heat lamp. The start position for both ET and TT was 
Exposure Trial (ET)

A

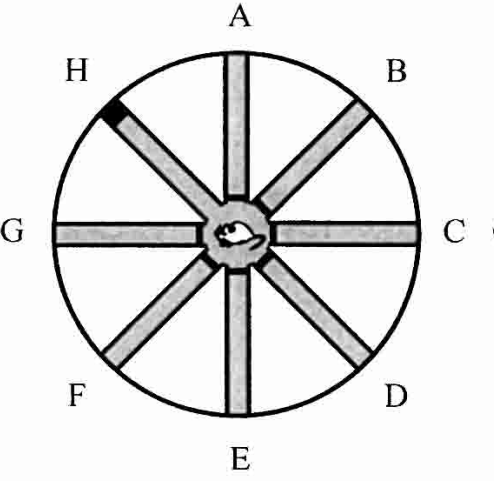

B
Test Trial (TT)

A

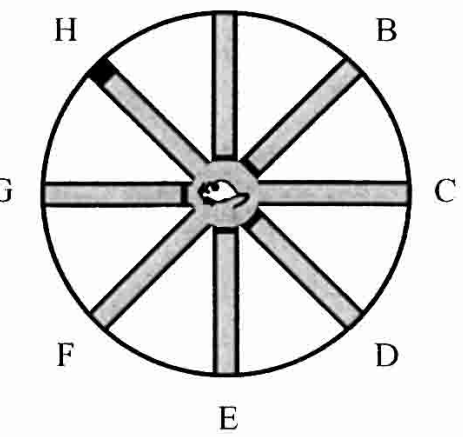

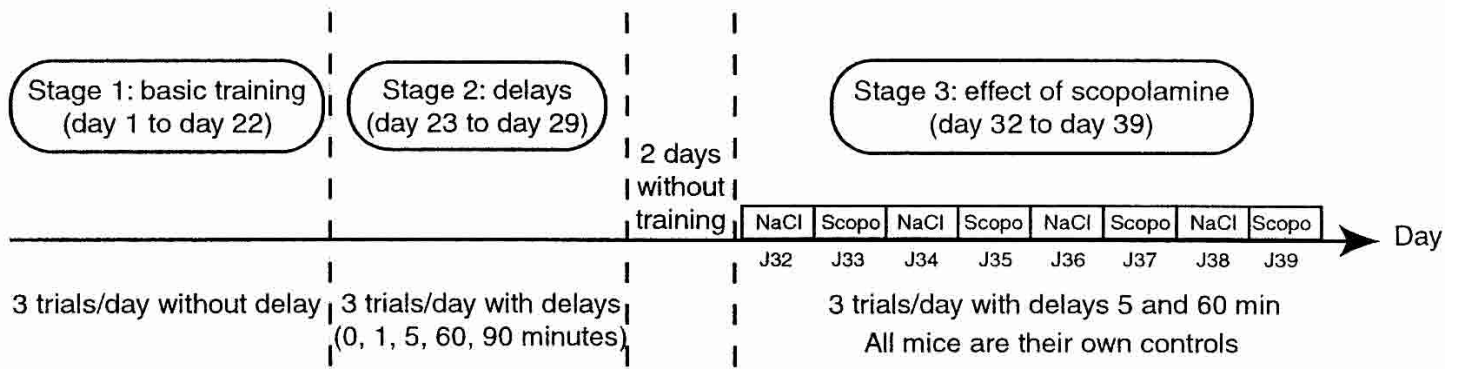

Figure 4 (A) Spatial working memory task. Schematic representation of the protocol. The radial-arm water maze is composed of 8 arms (A-H) radiating from a central area. During an exposure trial (left, Exposure Trial, ET), only one arm is available and contains the platform (here, arm $\mathrm{H}=$ target arm). During a subsequent test trial (right, Test Trial, $\Pi$ ), three arms are available. The task for the mouse is to return to the target arm without visiting arms with no platform. A delay of variable duration may be introduced during the retention interval between the ET and the TT. (B) Schematic representation of the design used in Experiment 1. Experiment 1 consisted of three successive stages corresponding to basic training (days 1-22), delay effect (days 23-29), and effect of scopolamine (days 32-39). All mice are injected with saline and scopolamine in alternation (1 d saline, the next day scopolamine) before each daily trial (see text for further details).

controlled to avoid any egocentric strategies. For each session, a new arm among the three was used as the target arm. The daily sequence of arms was counterbalanced. When the mice had reached an asymptotic level of performance $(22 \mathrm{~d})$, they were tested with various RIs (delays) interposed between the ET and the TT (see below).

\section{Experiment 1}

After basic training without delay, male adult (10-months-old) wild-type $(n=11)$ and knockout $(n=11)$ mice were submitted to the second stage of the task, in which different delays $(0,1,5,60$, and $90 \mathrm{~min}$ ) were interposed between the ET and the TT (stage 2). Three different (short and long) delays were used per day (except for two trials on the last day), and presented in various sequences over seven successive days. Each delay was tested four times. Mice of both genotypes were tested in alternation.

Two days later, mice received daily intraperitoneal injections of scopolamine (scopolamine hydrobromide, $\mathrm{HBr}, 0.8 \mathrm{mg} /$ $\mathrm{kg}$, Scopo) in alternation with the vehicle $(\mathrm{NaCl}, 0.9 \%$, Sal) on eight successive days, resulting in four Scopo and four Sal injections (Fig. 4B). This dose of scopolamine was chosen as having selective effects on memory impairment, without significantly affecting locomotor behavior in C57/BL6 mice (Leblond et al. 2002). This was confirmed in $129 / \mathrm{Sv}$ mice in a preliminary study that showed that this treatment did not modify swim speed in wild-type and knockout mice submitted to a short-term (massed) learning task in the water maze (M.C. Buhot, unpubl.). Given the results of stage 2 , only delays 5 and 60 min were tested, again with three sessions per day. The effect of injection was assessed by comparing performance under saline condition with performance during stage 2 (no injection, same delays). The effect of the Scopo (compared with Sal) was evaluated with 5-min delay repeated four times, and delay $60 \mathrm{~min}$ repeated eight times. Given the fact that the effect of scopolamine in rodents at the dose used is maximal $20 \mathrm{~min}$ after injection and lasts $60 \mathrm{~min}$ (Durkin et al. 1992), the injections were carried out so that the drug could affect the ET or TT only, or both. For this reason, the three following timing modalities were used:

1. $20 \mathrm{~min}$ before ET for 5-min delay, the treatment has an effect on both ET and TT;

2. $30 \mathrm{~min}$ before ET for 60-min delay, the treatment has an effect on ET only;

3. 20 min before TT for 60 -min delay, the treatment has an effect on TT only.

\section{Experiment 2}

In the second experiment, 38 mice performed the task: eleven and twelve young-adult (3-month-old) wild type and knockout, respectively; eight and seven aged (22-months-old) wild type and knockout, respectively. The learning procedures were identical to that used in the preceding experiment. The delays used were 0,5 , $15,30,60$, and $90 \mathrm{~min}$. Mice were alternately submitted to the experiment with regard to their genotype and age.

\section{Data Collection and Statistical Analyses}

Animal's displacements in the maze were observed via a video monitor located in the room adjacent to the experimental room. The main parameter of performance, which was taken into account in the analyses of TT, was the ratio number of visits to the target arm/total number of visits (TA/V), a visit being defined as a swim into an arm at least beyond the first half of its length. The $\mathrm{TA} / \mathrm{V}$ measure of performance is not linked to swim speed, 
whereas the measure of latency in the classical Morris open water maze task is impacted by swim speed. A preliminary experiment aimed at optimizing the basic protocol for mice (number of arms to be used, intersession interval) allowed us to decide criteria of performance based on $\mathrm{TA} / \mathrm{V}$ as follows. A value of $\mathrm{TA} / \mathrm{V}=0.6$ corresponds to a performance at chance level. A value of TA/V = 0.8 corresponds to the threshold of a successful above-chance level performance. We also recorded the number of incomplete visits (IV) to arms that corresponded to swims without reaching the second half-length of arms. Incomplete visits are considered as indices of hesitation, of vicarious trial and error (VTE: see Tolman 1939; Amsel 1993; Bimonte and Denenberg 2000), and self-correction; they reveal more strategical aspects of the performance. Data were analyzed using ANOVAs with the Genotype (wild type and knockout), treatment (Scopo and Sal), and age (3and 22-month-old mice) as between-subject factors. For training, the repeated within-subject factor was the day (the average measure on the daily three trials). The effect of delay as the main within-subject factor was analyzed with five modalities in Experiment 1 delay effect $(0,1,5,60,90 \mathrm{~min})$, two modalities in Experiment 1 scopolamine effect $(5,60 \mathrm{~min})$, and six modalities in Experiment 2 age by genotype effect $(0,5,15,30,60,90 \mathrm{~min})$. Global analyses were followed, where appropriate, by independent analyses for each delay, for which the performance was compared with the chance level of performance using Student's $t$ tests. Scheffe's tests were also applied when necessary.

\section{ACKNOWLEDGMENTS}

This research was supported by the Centre National de la Recherche Scientifique and Université de Bordeaux 1. We thank Dr. T.P. Durkin for linguistic corrections of this manuscript and helpful discussions, M. Chaigniau for illustrations, Laboratoire de Transgénèse (Pr. J.-Y. Daniel) and D. Panzeri for their help in animal breeding and care, T. Lafon for his technical assistance with computers, and Pebeo for the generous supply of paint used for water maze testing. The authors would like to acknowledge anonymous referees for their help in improving an earlier version of the manuscript. Part of these results were presented at the Fifth IUPHAR Satellite Meeting on Serotonin, July 3-5, 2002, Acapulco, Mexico.

The publication costs of this article were defrayed in part by payment of page charges. This article must therefore be hereby marked "advertisement" in accordance with 18 USC section 1734 solely to indicate this fact.

\section{REFERENCES}

Amsel, A. 1993. Hippocampal function in the rat: Cognitive mapping or vicarious trial and error? Hippocampus 3: 251-256.

Bach, M.E., Barad, M., Son, H., Zhuo, M., Lu, Y.L., Shih, R., Mansuy, I., Hawkins, R.D., and Kandel, E.R. 1999. Age-related defects in spatial memory are correlated with defects in the late phase of hippocampal long-term potentiation in vitro and are attenuated by drugs that enhance the cAMP signaling pathway. Proc. Natl. Acad. Sci. 96: $5280-5285$.

Bachevalier, J. and Mishkin, M. 1986. Visual recognition impairment follows ventromedial but not dorsolateral prefrontal lesions in monkeys. Behav. Brain Res. 20: 249-261.

Barnes, C.A. and McNaughton, B.L. 1985. An age comparison of the rates of acquisition and forgetting of spatial information in relation to long-term enhancement of hippocampal synapses. Behav. Neurosci. 99: 1040-1048.

Beatty, W.W. and Bierley, R.A. 1986. Scopolamine impairs encoding and retrieval of spatial working memory in rats. Physiol. Psychol. 14: $82-86$.

Bimonte, H.A. and Denenberg, V.H. 2000. Sex differences in vicarious trial-and-error behavior during radial arm maze learning. Physiol. Behav. 68: 495-499.

Bimonte, H.A., Nelson, M.E., and Granholm, A.C.E. 2003. Age-related deficits as working load increases: Relationships with growth factors. Neurobiol. Aging 24: $37-48$.

Blalock, E.M., Porter, N.M., and Landfield, P.W. 1999. Decreased G-protein-mediated regulation and shift in calcium channel types with age in hippocampal cultures. J. Neurosci. 19: 8674-8684.

Brito, G.N.O., Davis, B.J., Stopp, L.C., and Stanton, M.E. 1983. Memory and the septo-hippocampal cholinergic system in the rat. Psychopharmacology 81: 315-320.

Buhot, M.C. 1997. Serotonin receptors in cognitive behaviors. Curr. Opin. Neurobiol. 7: 243-254.

Buhot, M.C., Patra, S.K., and Naïli, S. 1995. Spatial memory deficits following stimulation of hippocampal 5-HT1B receptors in the rat. Eur. J. Pharmacol. 285: 221-228.

Buhot, M.C., Martin, S., and Segu, L. 2000. Role of serotonin in memory impairment. Ann. Med. 32: 210-221.

Buhot, M.C., Wolff, M., Savova, M., Malleret, G., Hen, R., and Segu, L. 2003a. Protective effect of 5-HT1B receptor gene deletion on the age-related decline in spatial learning abilities in mice. Behav. Brain Res. 142: $135-142$.

Buhot, M.C., Wolff, M., and Segu, L. 2003b. Serotonin. In Memories are made of these (eds. G. Riedel and B. Platt). From messengers to molecules. 2. Principle Transmitters. Landes Bioscience, Georgetown, TX (in press).

Buresova, O., Bolhuis, J.J., and Bures, J. 1986. Differential effects of cholinergic blockade on performance of rats in the water tank navigation task and in a radial water maze. Behav. Neurosci. 100: $476-482$.

Burette, F., Jay, T., and Laroche, S. 2000. Synaptic depression of the hippocampal to prefrontal cortex pathway during a spatial working memory task. Curr. Psychol. Lett. 1: 9-23.

Cassel, J.C. and Jeltsch, H. 1995. Serotonergic modulation of cholinergic function in the central nervous system: Cognitive implications. Neuroscience 69: 1-41.

Cassel, J.C., Jeltsch, H., Neufang, B., Lauth, D., Szabo, B., and Jackisch, R. 1995. Downregulation of muscarinic- and 5-HT1B-mediated modulation of [3H]acetylcholine release in hippocampal slices of rats with fimbria-fornix lesions and intrahippocampal grafts of septal origin. Brain Res. 704: 153-166.

Clark, R.E., West, A.N., Zola, S.M., and Squire, L.R. 2001. Rats with lesions of the hippocampus are impaired on the delayed nonmatching-to-sample task. Hippocampus 11: 176-186.

Consolo, S., Arnaboldi, S., Ramponi, S., Nannini, L., Ladinsky, H., and Baldi, G. 1996. Endogenous serotonin facilitates in vivo acetylcholine release in rat frontal cortex through 5-HT1B receptors. J. Pharmacol. Exp. Ther. 277: 823-830.

Delatour, B. and Gisquet-Verrier, P. 1996. Prelimbic cortex specific lesions disrupt delayed-variable response tasks in the rat. Behav. Neurosci. 110: 1282-1298.

- 1999. Lesions of the prelimbic and infralimbic cortices in rats do not disrupt response selection but induce delay-dependent deficits: Evidence for a role in working memory? Behav. Neurosci. 113: 941-955.

Durkin, T.P. 1992. Spatial working memory over long retention intervals: Dependence on sustained cholinergic activation in the septohippocampal or nucleus basalis magnocellularis-cortical pathways? Neuroscience 62: 681-693.

Durkin, T.P., Messier, C., de Boer, P., and Westerink, B.H.C. 1992. Raised glucose levels enhance scopolamine-induced acetylcholine overflow from the hippocampus: An in vivo microdialysis study in the rat. Behav. Brain Res. 49: 181-188.

Eichenbaum, H., Otto, T., and Cohen, N.J. 1994. Two functional components of the hippocampo-memory system. Behav. Brain Sci. 17: $449-518$.

Floresco, S.B., Seamans, J.K., and Phillips, A.G. 1997. Selective roles for hippocampal, prefrontal cortical, and ventral striatal circuits in radial-arm maze tasks with or without a delay. J. Neurosci. 17: $1880-1890$.

Foster, T.C. 1999. Involvement of hippocampal synaptic plasticity in age-related memory decline. Brain Res. Rev. 30: 236-249.

Frick, K.M., Baxter, M.G., Markowska, A.L., Olton, D.S., and Price, D.L. 1995. Age-related spatial reference and working memory deficits assessed in the water maze. Neurobiol. Aging 16: 149-160.

Fuster, J.M. 2001. The prefrontal cortex-an update: Time is of the essence. Neuron 30: 319-333.

Ghoneim, M.M. and Mewaldt, S.P. 1975. Effects of diazepam and scopolamine on storage, retrieval and organizational processes in memory. Psychopharmacologia 44: 257-262.

. 1977. The interaction of scopolamine, diazepam and physostigmine in human memory. Psychopharmacologia 52: 1-6.

Goldman-Rakic, P. 1990. Cortical localization of working memory. In Brain organization and memory: Cells, systems and circuits. (eds. J.L. McGaugh, W. Weinberger, and G. Lynch) pp. 285-300. Oxford University Press, New York.

Granon, S. and Poucet, B. 2000. Involvement of the rat prefrontal cortex in cognitive functions: A central role for the prelimbic area Psychobiology 28: 229-237.

Granon, S., Vidal, C., Thinus-Blanc, C., Changeux, J.-P., and Poucet, B. 1994. Working memory, response selection, and effortful processing 
in rats with medial prefrontal lesions. Behav. Neurosci. 108: 883-891. Granon, S., Poucet, B., Thinus-Blanc, C., Changeux, J.-P., and Vidal, C. 1995. Nicotinic and muscarinic receptors in the rat prefrontal cortex: Differential roles in working memory, response selection, and effortful processing. Psychopharmacology 119: 139-144.

Hartmann, H., Velbinger, K., Eckert, A., and Müller, W.E. 1996. Region-specific downregulation of free intracellular calcium in the aged rat brain. Neurobiol. Aging 17: 557-563.

Hasselmo, M.E. and Wyble, B.P. 1997. Free recall and recognition in a network model of the hippocampus: Simulating effects of scopolamine on human memory function. Behav. Brain Res. 89: $1-34$.

Hironaka, N., Tanaka, K., Izaki, Y., Hori, K., and Nomura, M. 2001. Memory-related acetylcholine efflux from the rat prefrontal cortex and hippocampus: A microdialysis study. Brain Res. 901: 143-150.

Izquierdo, I. 1989. Mechanism of action of scopolamine as an amnestic. Trends Pharmacol. Sci. 10: 175-177.

Johnson, D.A., Zambon, N.J., and Gibbs, R.B. 2002. Selective lesion of cholinergic neurons in the medial septum by 192 IgG-saporin impairs learning in a delayed matching to position T-maze paradigm. Brain Res. 943: 132-141.

Kesner, R.P. and Hopkins, R.O. 2001. Short-term memory for duration and distance in humans: role of the hippocampus. Neuropsychology 15: $58-68$

Krawczyk, D.C. 2002. Contributions of the prefrontal cortex to the neural basis of human decision making. Neurosci. Biobehav. Rev. 26: 631-664.

Laroche, S., Davis, S., and Jay, T.M. 2000. Plasticity at hippocampal to prefrontal cortex synapses: Dual roles in working memory and consolidation. Hippocampus 10: 438-446.

Leblond, L., Beaufort, C., Delerue, F., and Durkin, T.P. 2002. Differential roles for nicotinic and muscarinic cholinergic receptors in sustained visuo-spatial attention? A study using a 5-arm maze protocol in mice. Behav. Brain Res. 128: 91-102.

Lee, I. and Kesner, R.P. 2003. Time-dependent relationship between the dorsal hippocampus and the prefrontal cortex in spatial memory. $J$. Neurosci. 23: 1517-1523.

Lehmann, O., Jeltsch, H., Lehnardt, O., Pain, L., Lazarus, C., and Cassel, J.-C. 2000. Combined lesions of cholinergic and serotonergic neurons in the rat brain using 192 IgG-saporin and 5,7-dihydroxytryptamine: neurochemical and behavioural characterization. Eur. J. Neurosci. 12: 67-79.

Lehmann, O., Jeltsch, H., Lazarus, C., Tritschler, L., Bertrand, F., and Cassel, J.-C. 2002. Combined 192 IgG-saporin and 5,7-dihydroxytryptamine lesions in the male rat brain: A neurochemical and behavioral study. Pharmacol. Biochem. Behav. 72: 899-912.

Malleret, G., Hen, R., Guillou, J.-L., Segu, L., and Buhot, M.-C. 1999. 5-HT1B receptor knock-out mice exhibit increased exploratory activity and enhanced spatial memory performance in the Morris water maze. J. Neurosci. 19: 6157-6168.

Milner, B., Petrides, M., and Smith, M.L. 1985. Frontal lobes and the temporal organization of memory. Hum. Neurobiol. 4: 137-142.

Mitchell, A.S., Dalrymple-Alford, J.C., and Christie, M.A. 2002. Spatial working memory and the brainstem cholinergic innervation to the anterior thalamus. J. Neurosci. 22: 1922-1928.

Nilsson, O.G. and Gage, F.H. 1993. Anticholinergic sensitivity in the aging rat septohippocampal system as assessed in a spatial memory task. Neurobiol. Aging 14: 487-497.

Olton, D.S., Becker, J.T., and Handelmann, G.E. 1979. Hippocampus, space, and memory. Behav. Brain Res. 2: 313-365.

Poucet, B. and Buhot, M.-C. 1989. Scopolamine impairs response-to-change based on distal cues in the rat. Physiol. Behav. 46: 355-359.

Poucet, B. and Buhot, M.-C. 1994. Effects of medial septal or unilateral hippocampal inactivations on reference and working spatial memory in rats. Hippocampus 4: $315-321$.

Ragozzino, M.E., Adams, S., and Kesner, R.P. 1998. Differential involvement of the dorsal anterior cingulate and prelimbic-infralimbic areas of the rodent prefrontal cortex in spatial working memory. Behav. Neurosci. 112: 293-303.

Rapp, P.R. and Amaral, D.G. 1989. Evidence for task-dependent memory dysfunction in the aged monkey. J. Neurosci. 9: 3568-3576.

Rosenzweig, E.S. and Barnes, C.A. 2003. Impact of aging on hippocampal function: Plasticity, network dynamics, and cognition. Prog. Neurobiol. 69: 143-179.

Ruotsalainen, S., Miettinen, R., MacDonald, E., Riekkinen, M., and Sirvio, J. 1998. The role of the dorsal raphe-serotonergic system and cholinergic receptors in the modulation of working memory. Neurosci. Biobehav. Rev. 22: 21-31.

Sarter, M. and Bruno, J.P. 1998. Age-related changes in rodent cortical acetylcholine and cognition: Main effects of age versus age as an intervening variable. Brain Res. Rev. 27: 143-156.

Seamans, J.K., Floresco, S.B., and Phillips, A.G. 1995. Functional differences between the prelimbic and anterior cingulate regions of the rat prefrontal cortex. Behav. Neurosci. 109: 1063-1073.

Shen, J., Barnes, C.A., Wenk, G.L., and McNaughton, B.L. 1996. Differential effects of selective immunotoxic lesions of medial septal cholinergic cells on spatial working and reference memory. Behav. Neurosci. 110: 1181-1186.

Soffié, M., Bronchart, M., and Lebailly, B. 1986. Scopolamine-induced deficits in acquisition of a complex spatial learning. Physiol. Behav. 37: 79-84.

Steckler, T. and Sahgal, A. 1995. The role of serotonergic-cholinergic interactions in the mediation of cognitive behaviour. Behav. Brain Res. 67: 165-199.

Steele, R.J. and Morris, R.G.M. 1999. Delay-dependent impairment of a matching-to-place task with chronic and intrahippocampal infusion of the NMDA-antagonist D-ASP5. Hippocampus 9: 118-136.

Tolman, E.C. 1939. Prediction of vicarious trial and error by means of schematic sowbug. Psychol. Rev. 46: 318-336.

Trillat, A.C., Malagie, I., Scearce, K., Pons, D., Anmella, M.C., Jacquot, C., Hen, R., and Gardier, A.M. 1997. Regulation of serotonin release in the frontal cortex and ventral hippocampus of homozygous mice lacking 5-HT1B receptors: In vivo microdialysis studies. J. Neurochem. 69: 2019-2025.

Walton, M.E., Bannerman, D.M., and Rushworth, M.F.S. 2002. The role of rat medial frontal cortex in effort-based decision making. J. Neurosci. 22: 10996-11003.

Wolff, M., Savova, M., Malleret, G., Hen, R., Segu, L., and Buhot, M.-C. 2003. Serotonin knockout mice exhibit a task-dependent selective learning facilitation. Neurosci. Lett. 338: $1-4$.

Xavier, G.F., Oliveira-Filho, F.J., and Santos, A.M. 1999. Dentate gyrus-selective colchicine lesion and disruption of performance in spatial tasks: Difficulties in 'place strategy' because of a lack of flexibility in the use of environmental cues? Hippocampus 9: $668-681$.

Zyzak, D.R., Otto, T., Eichenbaum, H., and Gallagher, M. 1995. Cognitive decline associated with normal aging in rats: A neuropsychological approach. Learn. Mem. 2: 1-16.

Received February 25, 2003; accepted in revised form June 16, 2003. 


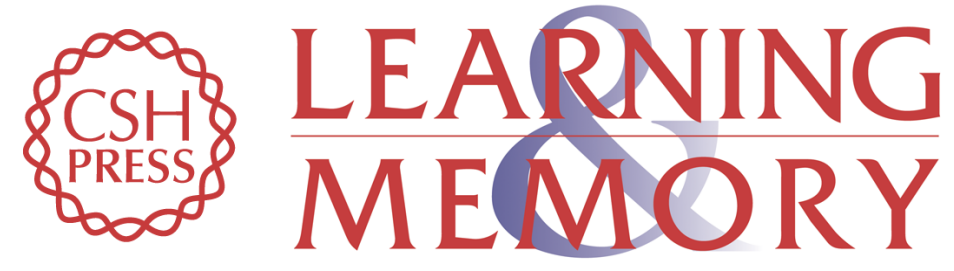

\section{Delay-Dependent Working Memory Impairment in Young-Adult and Aged 5-HT1BKO Mice as Assessed in a Radial-Arm Water Maze}

Mathieu Wolff, Narimane Benhassine, Pierre Costet, et al.

Learn. Mem. 2003, 10:

Access the most recent version at doi:10.1101/lm.60103

References This article cites 66 articles, 10 of which can be accessed free at: http://learnmem.cshlp.org/content/10/5/401.full.html\#ref-list-1

License

Email Alerting

Receive free email alerts when new articles cite this article - sign up in the box at the Service top right corner of the article or click here. 